\title{
The Belt and Road: Geographical pattern and regional risks
}

\author{
WU Shaohong ${ }^{1,2,3}$, LIU Lulu ${ }^{1,2,3}$, "LIU Yanhua ${ }^{1,2,3}$, GAO Jiangbo ${ }^{1,2}$, DAI Erfu ${ }^{1,2,3}$, \\ FENG Aiqing ${ }^{4}$, WANG Wentao ${ }^{5}$
}

1. Institute of Geographic Sciences and Natural Resources Research, CAS, Beijing 100101, China;

2. Key Laboratory of Land Surface Pattern and Simulation, CAS, Beijing 100101, China;

3. University of Chinese Academy of Sciences, Beijing 100049, China;

4. National Climate Center, China Meteorological Administration, Beijing 100081, China,

5. Administrative Center for China Agenda 21, Beijing 100862, China

\begin{abstract}
Building the Belt and Road is initiatives of China to promote win-win international cooperation in the new era, aiming at green, health, intellect and peace and the joint development with people of the countries along the route. Systematic analysis on environmental characteristics, evolutionary tendency and future risks are certainly the scientific fundamentals of sustainable development for the Belt and Road construction. Applied remote sensing monitoring, statistical analysis, this paper investigates the regional characteristics of climate, topography, soil, hydrology, vegetation cover and terrestrial ecosystems production, as well as socio-economic conditions. Based on the regional characteristics, the Belt and Road is divided into 9 sub-regions: Central and Eastern Europe sub-region with cold and humid climate, Mongolia and Russia sub-region with cold and arid climate, Central and West Asia arid sub-region, Southeast Asia sub-region with warm and humid climate, Pakistan arid sub-region, Bangladesh-India-Myanmar sub-region with warm and humid climate, Eastern China monsoon sub-region, Northwest China arid sub-region and Tibetan Plateau sub-region. Combining modeling simulation with scenario projections, natural disaster assessment methodology is used to assess the risk of extreme events including heat waves, droughts and floods in the coming 30 years (2021-2050). Results show that, on the basis of the regional framework, the western Eurasia would be a warming trend; both sides of Qinghai-Tibet Plateau in high temperature and heat waves risk; Central and Eastern Europe sub-region with cold and humid climate in high drought risk; Bangladesh-India-Myanmar sub-region with warm and humid climate as well as Eastern China in high risk of flooding.
\end{abstract}

Keywords: the Belt and Road; regional characteristics; extreme events; environmental change; risks

Received: 2018-08-12 Accepted: 2018-11-22

Foundation: Key Project of National Natural Science Foundation of China, No.41530749; Strategic Priority Research Program of the Chinese Academy of Sciences, No.XDA20020202, No.XDA19040304

Author: Wu Shaohong, Professor, specialized in physical geography. E-mail:wush@igsnrr.ac.cn

*Corresponding author: Liu Yanhua, Professor, specialized in environmental renovation and global change.

E-mail:liuyh@most.gov.cn 


\section{Introduction}

Construction of the Belt and Road is initiatives of China to promote international win-win cooperation in the new era, the objectives of which are to "practice the new idea of green development, advocate the green, low-carbon, cycling, and sustainable production and life style, strengthen the environmental cooperation, construct the ecological civilization, and jointly achieve the goal of sustainable development in 2030" (Xi, 2017). The main body of the Belt and Road lies across the Asian-African and European continents and is connected in the east to the flourishing Asian-Pacific economic circle and linked in the west to the developed European economic area, with many countries in the middle hinterland (Figure 1). Construction of the Belt and Road will bring enormous profit to the countries along the route. However, the differences in the conditions of resource environments are huge, and the environments are fragile; these aspects have a profound influence on regional socio-economic development (Ma, 2007; Dong et al., 2015). Therefore, it is among the important measures for cooperation to enrich environmental and biological diversity, strengthen the protection of natural resources, adapt to climate change, resist and reduce disasters, improve the ability of disaster risk management, and promote cooperation in the fields of renewable energy and energy efficiency (NDRC et al., 2015); a series of relevant studies is in progress (Zou et al., 2015; Chen et al., 2016; Liu, 2016; Cui, 2017; Ge et al., 2017;Yao and Guo, 2017; Zhu, 2017).

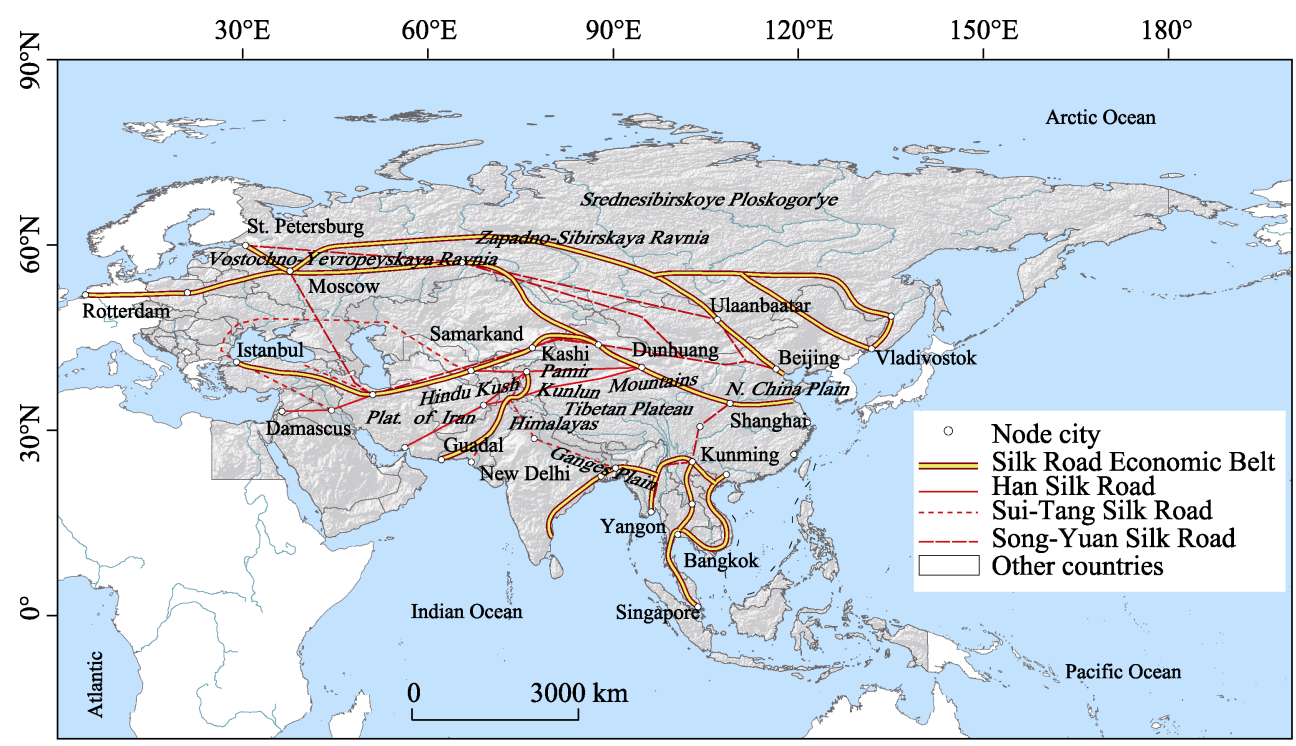

Figure 1 The covered regions and the current and historical pathways for the Belt and Road

The promotion of regional sustainable development and building of the "green silk road" are the guarantees for the construction of the Belt and Road to achieve success (Li et al., 2015; Dong et al., 2017). Particularly, the full understanding of the characteristics and risks of regional environment (Li et al., 2014) is the basis of the construction of the Belt and Road and the sustainable development of the environment (NRSCC et al., 2015; Li et al., 2016; 
$\mathrm{Xu}$ et al., 2016). In this study, under the background of climate change and in the face of construction of the Belt and Road, the countries along the Belt and Road are taken as a whole, analyzing environment, resources, regional differentiation as well as changing trend. Extreme event risks are paid more attention to for supporting the socio-economic development and carrying forward the ecological civilization construction of the Belt and Road. Scientifically, the purposes of the study are to get better understanding of the basic characteristics of nature of the Belt and Road from the point of view of regions, advantages and disadvantages in nature. The study also can provide necessary and effective scientific basis for management and protection of physical environment, natural disaster reduction, as well as the win-win construction of the Belt and Road.

\section{Data source and analytic method}

\subsection{Data source}

Of environmental factors, air temperature, precipitation, humidity, and runoff depth are the active and variable factors (Ding, 2010). Vegetation type/function change with the variable factors, which was given attention as well. Factors of terrain and soil were taken as relatively stable factors (Wu, 2008). The data source, duration, and spatial resolution of studies are shown in Table 1. Based on the simulation experiments on the past and scenario estimation of HadGEM2-ES model and the scenario of RCP8.5, the period of 1971-2000 was taken as baseline period and 2021-2050 as study period.

\subsection{Methods}

2.2.1 Characterization of spatial patterns of the resource environmental factors in the Belt and Road ArcGIS spatial analysis tool was applied to extract the values of factors and to obtain the spatial patterns for the resources and environmental factors in the Belt and Road

Table 1 The data sources for terrestrial areas of the Belt and Road

\begin{tabular}{|c|c|c|c|}
\hline Index & Data source & Duration & Spatial resolution \\
\hline Terrain & National Centers for Environmental Information & 2009 & $1 \mathrm{~km}$ \\
\hline Soil & Harmonized World Soil Database & 2012 & $1 \mathrm{~km}$ \\
\hline Land-cover & $\begin{array}{l}\text { Centre for Earth System Science, Tsinghua } \\
\text { University }\end{array}$ & 2014 & $250 \mathrm{~m}$ \\
\hline Protected areas & World Database on natural reserves & 2017 & Reserve area \\
\hline Temperature & Met Office Hadley Centre & $1950-2050$ & $0.5^{\circ} * 0.5^{\circ}$ \\
\hline Precipitation & Met Office Hadley Centre & $1950-2050$ & $0.5^{\circ} * 0.5^{\circ}$ \\
\hline SPEI & Spanish National Research Council & $1950-2004$ & $0.5^{\circ} * 0.5^{\circ}$ \\
\hline Runoff depth & Potsdam Institute for Climate Impact Research & $1971-2050$ & $0.5^{\circ} * 0.5^{\circ}$ \\
\hline NPP & Potsdam Institute for Climate Impact Research & $1971-2050$ & $0.5^{\circ} * 0.5^{\circ}$ \\
\hline Grain yield $^{*}$ & Global Gridded Crop Model Intercomparison & $1951-2050$ & $0.5^{\circ} * 0.5^{\circ}$ \\
\hline GDP & World Bank & $1960-2016$ & Countries \\
\hline
\end{tabular}

Note: *: Grain yield is the sum of rice, wheat, maize, and soybean production. 
On that basis, the past culture, strategic layout of the Belt and Road, socio-economic development, and climatic environment characteristics were taken as the main reference indexes, which were supplemented by other resource environmental indicators to identify the regional differentiation rules of the Belt and Road. By the methodology for the regionalization of the eco-geographic regional system in China (Zheng, 2008), the natural characteristics as well as factors of human activities and national integrity were taken into account to identify the regional differences.

\subsubsection{Extreme event risk projection}

(1) Trend analysis of variations in the environmental factors

According to the area-weighted average method of longitude-latitude grids (Jones and Hulme, 1996), the annual averages of resource environmental factors such as, air temperature, precipitation, depth of runoff, net primary productivity (NPP), and grain yield, in different regions of the Belt and Road were calculated. The algorithm was as following:

$$
\bar{X}=\frac{\sum_{i=1}^{n}\left(\cos \left(\alpha_{i}\right) \times \frac{1}{k_{i}} \sum_{j=1}^{k_{i}} x_{j}\right)}{\sum_{i=1}^{n} \cos \left(\alpha_{i}\right)},
$$

where $\bar{X}$ is the regional annual average of the calculated factor $x, \alpha_{i}, i=1,2, \ldots, n$ is the longitude and latitude for the grid's central point, $n$ is the number of grids, and $x_{j}, j=1,2, \ldots, k_{i}$ is the value of environmental factor in the $i$ th grid. The method of univariate linear fitting and trend analysis are adopted to evaluate the variation trends of resource environmental factors during 2021-2050 in different sub-regions of the Belt and Road. Then a significance test is conducted.

(2) Extreme events risk classes

Heat wave index (HI, GB/T 29457-2012), composite index of meteorological drought (CI, GB/T 20481-2006) and flood index (FI, namely the number of times that the maximum 3-day precipitation) were applied to calculate the frequency for the occurrence of three extreme events at different levels and further adopted the superposition analysis method to obtain the risk of extreme events (Table 2).

Table 2 Classification of extreme events hazards including droughts (CI), heat waves (HI) and floods (FI)

\begin{tabular}{lccc}
\hline \multirow{2}{*}{ Levels } & \multicolumn{3}{c}{ Index } \\
\cline { 2 - 4 } & $\mathrm{CI}$ & $\mathrm{HI}$ & FI \\
\hline Mild & $-1.8<\mathrm{CI} \leqslant-1.2$ & $2.8 \leqslant \mathrm{HI}<6.5$ & $30(35)-150 \mathrm{~mm}$ \\
Moderate & $-2.4<\mathrm{CI} \leqslant-1.8$ & $6.5 \leqslant \mathrm{HI}<10.5$ & $150-250 \mathrm{~mm}$ \\
Severe & $\mathrm{CI} \leqslant-2.4$ & $\mathrm{HI} \geqslant 10.5$ & $\geqslant 250 \mathrm{~mm}$ \\
\hline
\end{tabular}

\section{Regional differences}

\subsection{Natural environment characteristics}

The terrestrial areas of the Belt and Road are from China, pass through Central Asia and Russia to Europe (the Baltic Sea), West Asia to the Persian Gulf and the Mediterranean, and 
extend to Southeast Asia, South Asia, and the Indian Ocean. The range of the areas is vast, and the environmental conditions are complicated and diverse.

(1) Various climates

According to the Köppen climate classification system (Köppen, 1900), terrestrial areas of the Belt and Road cover all the five climate zones (Tropical climates, Arid climates, Temperate climates, Cold climates, and Polar climates) and most climate types of the system. It passes through the tropics, temperate zones, and frigid zones and traverses monsoon, continental, and desert climates (Figures $2 \mathrm{a}$ and $2 \mathrm{~b}$ ). Most areas show a warming trend. The warming rate is relatively slower in the lower latitude areas with higher temperature while that is faster in the high latitude areas with lower temperatures. In humid Southeast Asia and South Asia the precipitation has increased, but the trend is not obvious. Precipitation in the arid and semi-arid regions of Central and West Asia, Northwest China, Mongolia, Russia and Central and Eastern Europe increases significantly.

(2) Complex terrain

The area includes the majestic mountains of the Himalayas, Kunlun Mountain, and Hindu Kush Mountains as well as the vast Tibetan Plateau, Pamirs, Iranian Plateau, the fertile plains of North China, the Ganges River, and Eastern Europe (Figure 1).
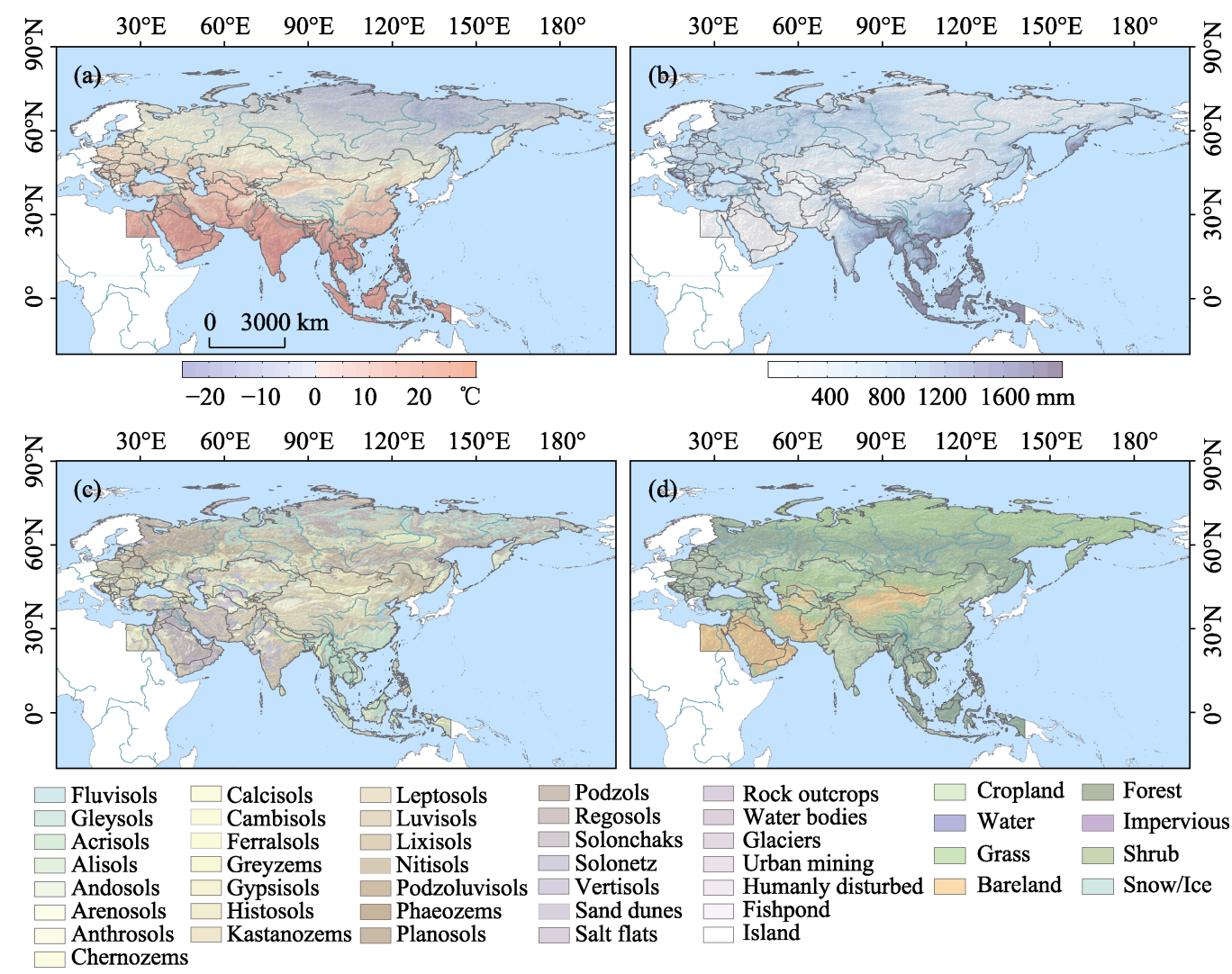

Figure 2 The spatial distribution of annual average of environmental factors (a. temperature; b. precipitation; c. soil types; and d. vegetation cover) of the Belt and Road

(3) Abundant soil 
Soils in this area consist of a total of more than 30 types (NRSCC et al., 2015). Leptosols are most widely distributed, followed by Gleysols, Podzols, and Cambisols (Figure 2c).

(4) Varying hydrology

The spatial distribution of multi-decadal average runoff depth is consistent with that of precipitation. The region with the highest runoff depth is mainly located in South Asia and Southeast Asia, the runoff depth in Eastern Siberia, Mongolia, Central Asia, and West Asia is relatively low, and the runoff depth in Northwest China and in part of the Arabian Peninsula is the lowest.

(5) Heterogeneous vegetation

The forests are mainly distributed in Southeast Asia, Eastern China, Southern Siberia, and the north of Eastern European Plain, the grasses and shrubs are mainly distributed in the eastern Tibetan Plateau, Mongolia, Kazakh hills, and Caspian lowland, and the croplands are mainly distributed in Eastern China, the Indochina Peninsula, the Indian Peninsula, the southern region of the West Siberian Plain, and the coast of the Black Sea (NRSCC et al., 2015). Vegetation NPP gradually declines from the eastern and western edges of Eurasia towards the heartland (Figure 2d).

\subsection{Socio-economic situations}

Until 2015, the total sum of the gross domestic products (GDP) of 65 countries of the Belt and Road reached \$21 trillion, which accounted for 29\% of the GDP of the world. In particular, the GDP of China increased from \$200 billion at the beginning of the reform and opening-up to $\$ 11$ trillion, and its share in the world increased from $5 \%$ to $15 \%$. On the other hand, except for India, Russia, Indonesia, Saudi Arabia and Turkey, the economic developing level of most countries along the Belt and Road is relatively low. Meanwhile, the eco-environmental problems caused by economic development are urgently in need of economic structural transformation to enable sustainable development (Liu, 2017).

\subsection{Recognition identification of natural regions}

Based on differences of climate, terrain, soils, hydrology, and vegetation; considering historical and cultural background, and socio-economic developmental level, as well as advantage of the six major economic corridors $(\mathrm{Xi}, 2017)$; guided by the dividing methodology of the eco-geographical regional system of China (Zheng et al., 2008) and the Köppen climate classification (Köppen, 1900); the terrestrial areas of the Belt and Road are identified as nine sub-regions (Figure 3 and Table 3): Central and Eastern Europe sub-region with cold and humid climate (CEE), Mongolia and Russia sub-region with cold and arid climate (MR), Central and West Asia arid sub-region (CWA), Southeast Asia sub-region with warm and humid climate (SEA), Pakistan arid sub-region (PAK), Bangladesh-India-Myanmar sub-region with warm and humid climate (BIM), Eastern China monsoon sub-region (CNE), Northwest China arid sub-region (CNW), and Tibetan Plateau sub-region (TIB).

\subsection{Regional characteristics}

Climate, terrain, soil, hydrology, vegetation NPP of the nine sub-regions are shown in Table 3 , which displays great differences in the environment between regions. 


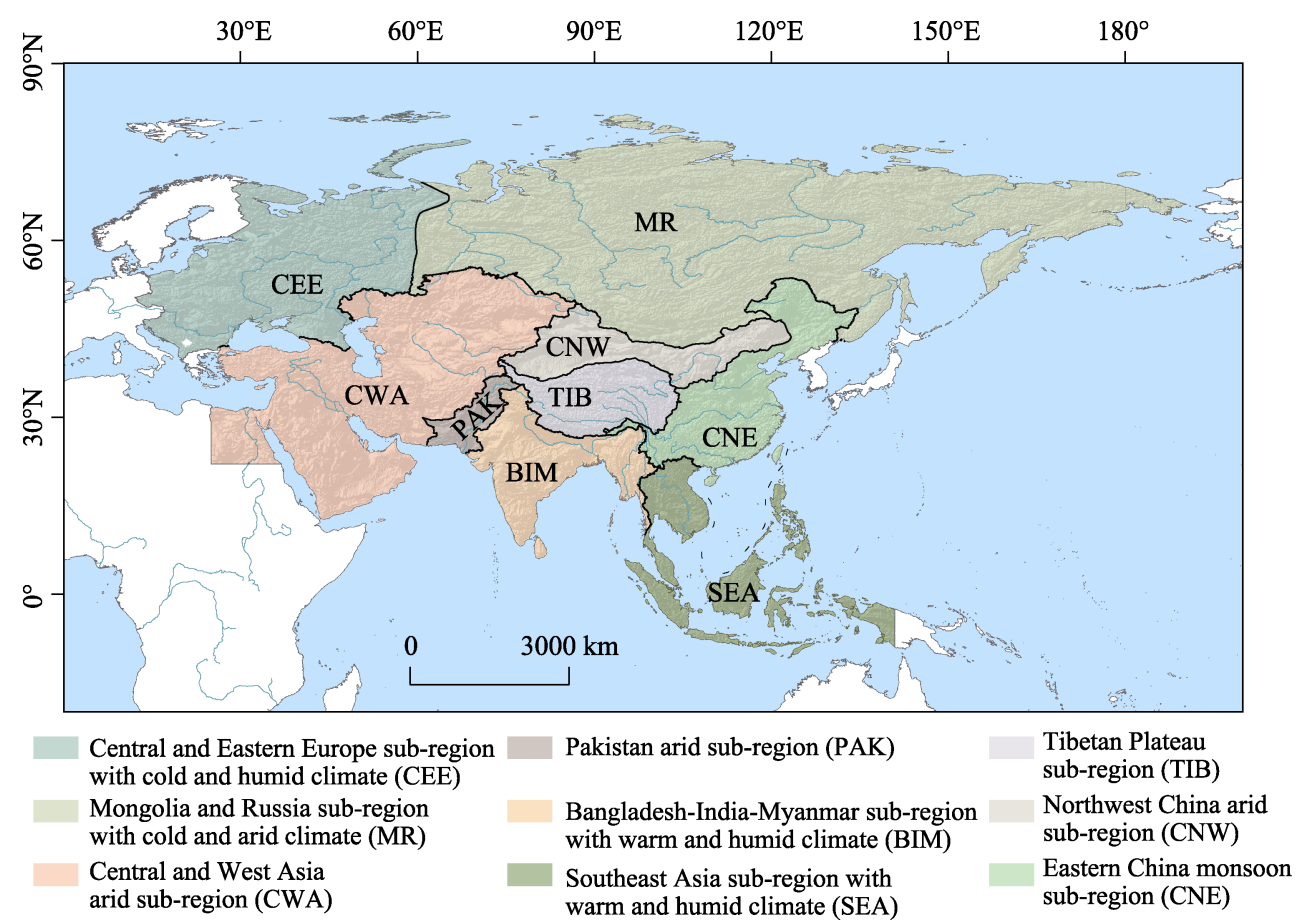

Figure 3 Sub-regions of the Belt and Road

\section{Extreme event risks}

According to AR5 (the Fifth Assessment Report) of the Intergovernmental Panel on Climate Change (IPCC) (IPCC, 2013), the areas of the Belt and Road are sensitive to climate change. The weather and climate extreme events happen frequently, which would very likely cause increasing in risks of natural disasters and harm to the socio-economic. Projection of future environmental risk would help for adapting to climate change and avoiding natural disaster risks in the socio-economic construction. Risk levels for extreme events of heat waves, droughts, and floods were obtained based on the baseline (1971-2000) and future (RCP8.5, 2021-2050) climate data.

\subsection{Variations in the environmental factors}

The trend analysis and spatial distribution indicate that (Table 4 and Figure 4) temperature exhibits an ascending trend in the vast majority of sub-regions, which passes the significance test at the 0.05 level (Figure 4a). The overall trend in precipitation is not apparent. Precipitation increases and decreases without high significance, but its regional differences are obvious (Figure 4b). Variations in runoff depth (Figure 4c) would increase extreme events, which are very likely to cause the occurrence of disaster events (Figure 4d). The variations in the environmental climate-hydrological factors are significant. The results of such changes imply that those variations are most likely to increase major natural disasters arising from heat waves, droughts, and floods (Table 4). 


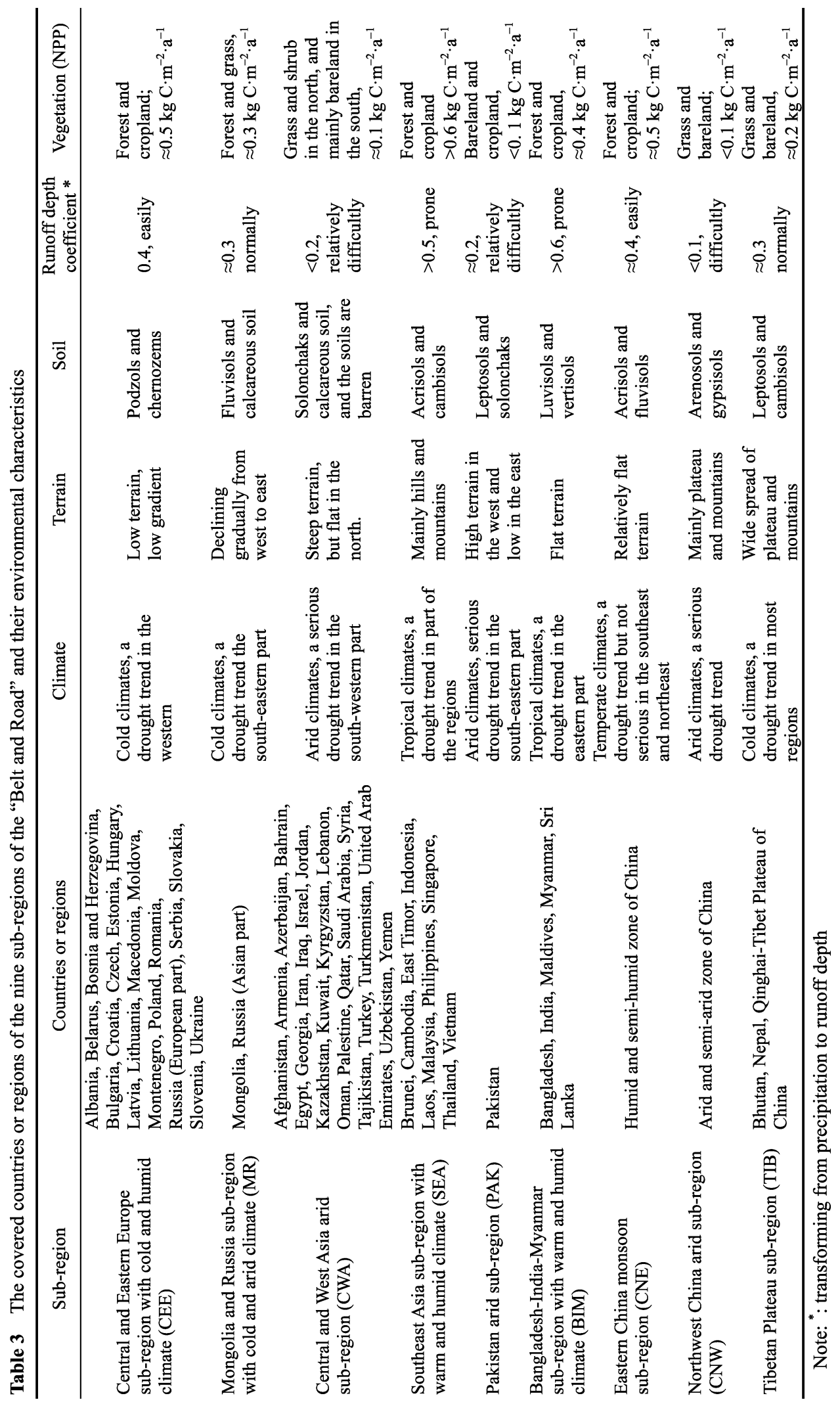


Table 4 The projected trends of different factors during 2021-2050

\begin{tabular}{|c|c|c|c|c|c|c|c|c|c|c|}
\hline & \multicolumn{2}{|c|}{$\begin{array}{l}\text { Temperature } \\
\left({ }^{\circ} \mathrm{C} / 10 \mathrm{a}\right)\end{array}$} & \multicolumn{2}{|c|}{$\begin{array}{l}\text { Precipitation } \\
\quad(\mathrm{mm} / 10 \mathrm{a})\end{array}$} & \multicolumn{2}{|c|}{$\begin{array}{l}\text { Runoff depth coefficient } \\
\qquad\left(10^{-3} / 10 \mathrm{a}\right)\end{array}$} & \multicolumn{2}{|c|}{$\begin{array}{c}\mathrm{NPP} \\
\left(\mathrm{gC} \cdot \mathrm{m}^{-2} / 10 \mathrm{a}\right)\end{array}$} & \multicolumn{2}{|c|}{$\begin{array}{l}\text { Grain yield } \\
\left(\mathrm{t} \cdot \mathrm{ha}^{-1} / 10 \mathrm{a}\right)\end{array}$} \\
\hline & RCP4.5 & RCP8.5 & RCP4.5 & RCP8.5 & $\mathrm{RCP} 4.5$ & RCP8.5 & $\mathrm{RCP} 4.5$ & RCP8.5 & RCP4.5 & RCP8.5 \\
\hline CEE & $0.405^{*}$ & 0.305 & -0.132 & -7.83 & -1.22 & 0.14 & 17.3 & $10.0^{*}$ & -0.0573 & $-0.308^{*}$ \\
\hline MR & $0.725^{*}$ & $0.682^{*}$ & $16.1^{*}$ & 8.80 & 2.82 & -0.65 & $18.9^{*}$ & $24.9^{*}$ & $0.122^{*}$ & $0.175^{*}$ \\
\hline SEA & $0.275^{*}$ & $0.422^{*}$ & 16.0 & 49.9 & 3.24 & 3.26 & 15.1 & $33.8^{*}$ & -0.0606 & $-0.249^{*}$ \\
\hline CWA & $0.495^{*}$ & $0.605^{*}$ & 5.24 & $-13.2^{*}$ & 3.50 & 0.78 & 4.87 & $-0.283^{*}$ & 0.0082 & $-0.200^{*}$ \\
\hline PAK & $0.476^{*}$ & $0.530^{*}$ & -6.00 & -17.4 & -1.22 & 5.28 & -1.20 & $4.14^{*}$ & -0.321 & -0.304 \\
\hline BIM & $0.424^{*}$ & $0.582^{*}$ & -5.38 & -44.8 & -0.35 & -4.71 & 5.11 & $19.7^{*}$ & -0.358 & $-0.424^{*}$ \\
\hline $\mathrm{CNE}$ & $0.352^{*}$ & $0.587^{*}$ & 5.49 & 18.1 & -6.12 & -2.54 & 10.5 & $28.3^{*}$ & -0.0271 & 0.203 \\
\hline CNW & $0.310^{*}$ & $0.646^{*}$ & 0.275 & 0.823 & -0.097 & -2.72 & 1.75 & $2.75^{*}$ & -0.0146 & 0.040 \\
\hline TIB & $0.544^{*}$ & $0.585^{*}$ & 0.335 & 4.18 & -0.71 & -1.18 & $-0.220^{*}$ & $32.0^{*}$ & $0.0856^{*}$ & $0.151^{*}$ \\
\hline
\end{tabular}

Note: ${ }^{*}$ : passed the significance test of 0.05 level.

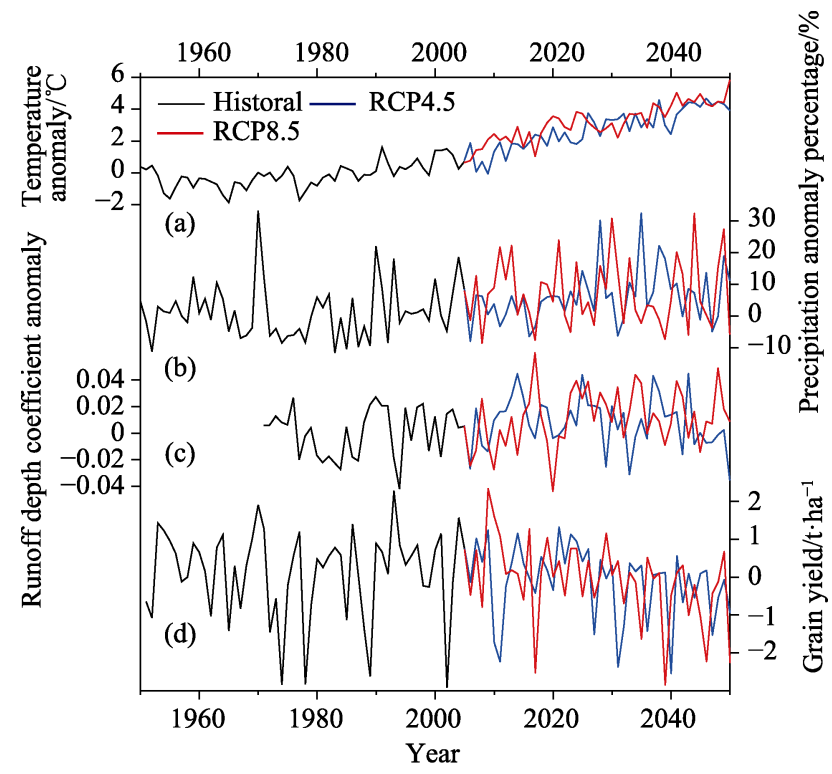

Figure 4 Annual mean changes of different resources and environment factors in typical regions (a. temperature increase in MR; b. precipitation fluctuation in SEA; c. runoff coefficients variation in CNE; d. crop yield decreases in BIM; baseline period is from 1971 to 2000)

\subsection{Risk of heat wave events}

The high risk areas of heat waves are mainly distributed in the southern part of Eastern China monsoon sub-region, the western part of Northwest China arid sub-region, the northern part of Central and West Asia arid sub-region, Southeast Asia sub-region with warm and humid climate, and part of the southern region of Central and Eastern Europe sub-region with cold and humid climate, especially in the mid-lower latitude areas. The total area of 


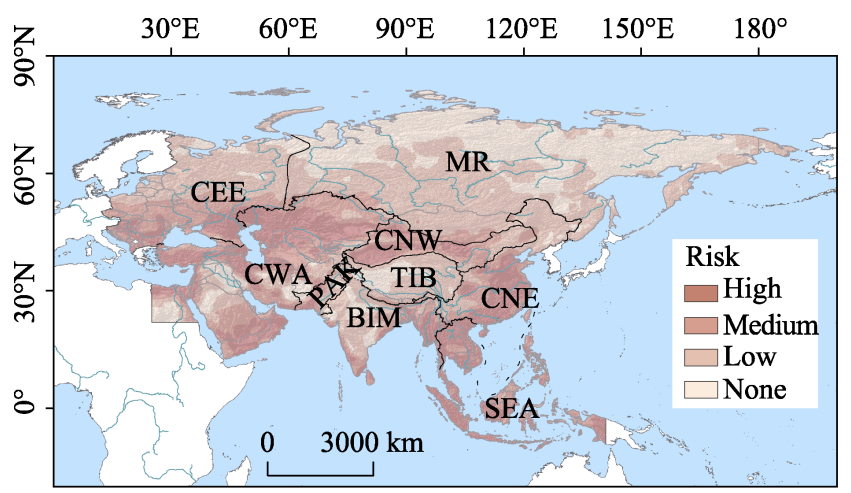

Figure 5 Heat wave hazard risks for the Belt and Road high heat wave risk would be 11.8 million $\mathrm{km}^{2}$, which takes $23.4 \%$ of the total area of the Road and Belt. And approximately 1.8 billion people would be affected, occupying $35.6 \%$ of the total population. These areas hold total GDP of 30.5 trillion USD, or $44.3 \%$ of the total GDP. The areas, which might reach medium heat wave risk, are mainly distributed in the western part of Eastern China monsoon sub-region, the central and southern parts of Central and West Asia arid sub-region, the eastern part of Bangladesh-India-Myanmar sub-region with warm and humid climate, and the western part of Pakistan arid sub-region (Figure 5). The affected area would reach 22.2 million $\mathrm{km}^{2}$, or $44.3 \%$ of the total area of the Road and Belt. Nearly 3 billion people would be affected, which would be $57 \%$ of the total population. These areas hold total GDP of 45.9 trillion USD, or $66.6 \%$ of the total GDP. Heat waves harm human health, increase the risk of disease and death, affect agriculture, forestry and animal husbandry production, aggravate the degree of drought, and damage crop growth. Increases in heat wave intensity are generally $0.5-1.5^{\circ} \mathrm{C}$ above a given global warming threshold. In particular, in the regions of the Mediterranean coast and Central Asia, the increase in the strength of heat waves is more rapid (Perkins-Kirkpatrick and Gibson, 2017). The future precipitation in some regions of the Belt and Road is expected to decrease, and the warming and drying climate trend will likely cause heat wave events with increasingly serious hazards.

\subsection{Risk of drought events}

The high drought risk areas are mainly distributed in the western part of Central and Eastern Europe sub-region with cold and humid climate, the northern part of Central and West Asia arid sub-region, the north-eastern part of Pakistan arid sub-region, part of Southeast Asia sub-region with warm and humid climate, Tibetan Plateau sub-region, the western part of Northwest China arid sub-region, and the southern part of Eastern China monsoon sub-region. The total area of high drought risk would be 3.64 million $\mathrm{km}^{2}$, or $7.2 \%$ of the total area of the Road and Belt. And approximate 0.43 billion people would be affected, being $8.2 \%$ of the total population. These areas hold total GDP of 7.1 trillion USD, or $10.4 \%$ of the total GDP. The areas, which might reach me-

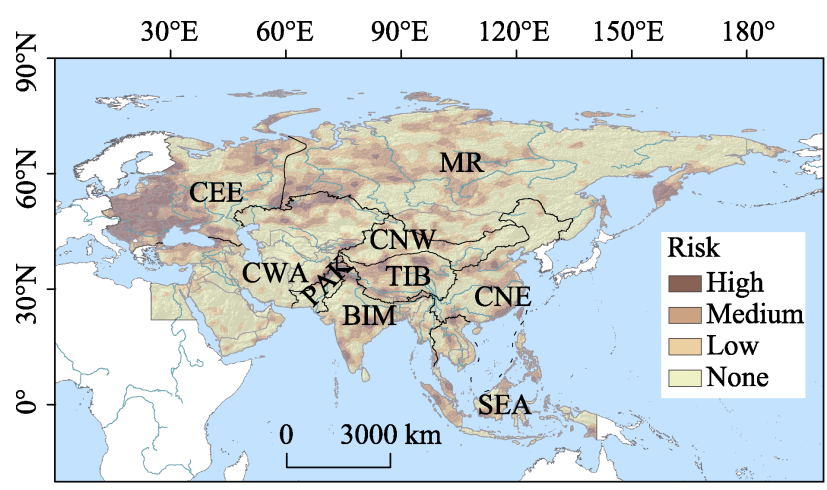

Figure 6 Drought hazard risks for the Belt and Road 
dium drought risk are distributed in the northeastern part of Central and Eastern Europe sub-region with cold and humid climate, the central and western part of Mongolia and Russia sub-region with cold and arid climate, and the southern part of Bangladesh-India-Myanmar sub-region with warm and humid climate (Figure 6). The affected area would reach 11.43 million $\mathrm{km}^{2}$, or $26.5 \%$ of the total area of the Road and Belt. Nearly 1.44 billion people would be affected, or $27.6 \%$ of the total population. These areas hold total GDP of 21.1 trillion USD, or $30.7 \%$ of the total GDP. Drought events will cause a series of problems that include economic losses, ecological degradation and social unrest (Zhang et al., 2016). In the context of climate warming, the occurrence frequency of drought events in the Belt and Road is higher, the duration time is longer, the range of impact is larger, and the influences on agriculture, water resource, ecology and socio-economy are also more serious.

\subsection{Risk of flood events}

The areas of high flood risk mainly appear in the southern and northern parts of Bangladesh-India-Myanmar sub-region with warm and humid climate, the eastern part of Eastern China monsoon sub-region, and the southern part of Pakistan arid sub-region. The total area of high flood risk would be 3.4 million $\mathrm{km}^{2}$, making up $6.7 \%$ of the total area of the Road and Belt. And approximately 1.7 billion people, or $31.8 \%$ of the total population, would be affected. These areas hold total GDP of 22.9 trillion USD, or 33.2\% of the total GDP. The areas, which might reach medium flood risk, mainly appear in the eastern part of Mongolia and Russia sub-region with cold and arid climate, the western and northern parts of Eastern China monsoon sub-region, part of Southeast Asia sub-region with warm and humid climate, the northern part of Pakistan arid sub-region, and the southern part of Central and West Asia arid sub-region (Figure 7). The affected area would reach 10.5 million $\mathrm{km}^{2}$, taking $20.8 \%$ of the total area of the Road and Belt. Nearly 3 billion people would be affected, accounting for $56.9 \%$ of the total population. These areas hold total GDP of 37.8 trillion USD, or $54.9 \%$ of the total GDP. Flood events destroy the living environments of human beings and biological growth environments and cause losses to human life and property and to the socio-economy. The strengths of future flood events in the Belt and Road gradually increase with global warming, especially in the middle and low-latitude regions, where the precipitation strength is high and the hazard range is large. The increase in exposed range indicates the necessity of adopting adaptive measures prior to significant warming (Hirabayashi et al., 2013).

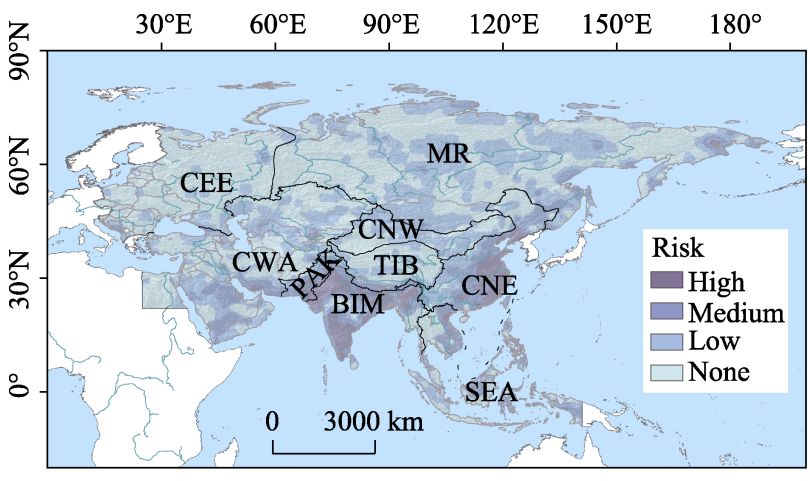

Figure 7 Flood hazard risks for the Belt and Road

\section{Conclusions}

The main conclusion through analysis and comparison of regional characteristics and 
changing trends of resource environmental factors for terrestrial areas of the Belt and Road, and assessment of the extreme event risks under the future scenario of climate change are:

(1) Environment of the Belt and Road as a whole has definite regional difference, which could be identified into nine sub-regions based on regional characteristics of climate, terrain, soils, hydrology and vegetation. The nine sub-regions are: Central and Eastern Europe sub-region with cold and humid climate (CEE), Mongolia and Russia sub-region with cold and arid climate (MR), Central and West Asia arid sub-region (CWA), Southeast Asia sub-region with warm and humid climate (SEA), Pakistan arid sub-region (PAK), Bangladesh-India-Myanmar sub-region with warm and humid climate (BIM), Eastern China monsoon sub-region (CNE), Northwest China arid sub-region (CNW), and Tibetan Plateau sub-region (TIB).

(2) The environmental change along the Belt and Road is significant. The observations indicate an obvious warming trend, and the precipitation in most areas increases. It is estimated that the future warming rates in the middle and low-latitude regions will speed up, the regions with decreased precipitation will expand, and warming and drying trends will mainly appear in the western part of the Eurasian continent.

(3) Extreme events under climate change would increase and the future risk of natural disasters is prominent. The regions on two sides of the Tibetan Plateau are the high risk areas for heat waves. The eastern part of Central and Eastern Europe sub-region with cold and humid climate is the high risk area for droughts. Bangladesh-India-Myanmar sub-region with warm and humid climate and Eastern China monsoon sub-region are the high risk are as for floods.

Construction of the Silk Road economic belt in the future needs to establish an early warning system for the high-risk areas on the basis of risk evaluations for extreme events such as heat waves, droughts, and floods, strengthen the vulnerability assessments for different areas and industries, and establish an effective technical system to cope with extreme events.

\section{References}

Chen M X, Liu W D, Yeerken W et al., 2016. The impact of the Belt and Road Initiative on the pattern of the development of urbanization in China. Mountain Research, (5): 637-644. (in Chinese)

Cui P, 2017. International research project on natural disaster risk and integrated disaster reduction. Bulletin of Chinese Academy of Sciences, Z2: 26-28. (in Chinese)

Ding Y H, 2010. Climate Change. Beijing: China Meteorological Press. (in Chinese)

Dong S, Kolosov V, Li Y et al., 2017. Green development modes of the belt and road. Geography, Environment, Sustainability, 10(1): 53-69.

Dong S, Li Z, Li Y et al., 2015. Resources, environment and economic patterns and sustainable development modes of the Silk Road Economic Belt. Journal of resources and ecology, 6(2): 65-72.

Ge Q S, Jiang D, Lu F et al., 2017. Views on the study of geopolitical environment system simulation. Acta Geographica Sinica, 72(3): 371-382. (in Chinese)

Hirabayashi Y, Mahendran R, Koirala S et al., 2013. Global flood risk under climate change. Nature Climate Change, 3(9): 816-821.

IPCC, 2013. Climate Change 2013: The Physical Science Basis. Contribution of Working Group I to the Fifth Assessment Report of the Intergovernmental Panel on Climate Change. Cambridge, United Kingdom and New York, USA: Cambridge University Press. 
Jones P D, Hulme M, 1996. Calculating regional climatic time series for temperature and precipitation: Methods and illustrations. International Journal of Climatology, 16(4): 361-377.

Köppen W, 1900. Versuch einer Klassifikation der Klimate, vorzugsweise nach ihren Beziehungen zur Pflanzenwelt. Geographische Zeitschrift, 6(11.H): 593-611.

Li P, Qian H, Ken W et al., 2015. Building a new and sustainable "Silk Road Economic Belt". Environmental Earth Sciences, 74(10): 7267-7270.

Li X W, Zhang L, Guo H D et al., 2016. Space recognition of eco-environment global change response of arid and semi-arid region of the Silk Road Economic Belt. Bulletin of Chinese Academy of Sciences, 31(5): 559-566. (in Chinese)

Li Z H, Wang J L, Zhao Z P et al., 2014. Eco-environment patterns and ecological civilization modes in the Silk Road Economic Zone. Resources Science, (12): 2476-2482. (in Chinese)

Liu W D, 2015. Scientific understanding of the Belt and Road Initiative of China and related research themes. Progress in Geography, 34(5): 538-544. (in Chinese)

Liu W D, 2017.The Belt and Road Strategy Research. Beijing: The Commercial Press. (in Chinese)

Ma A N, 2007. Theoretical Geographical Science and Philosophy. Beijing: Higher Education Press. (in Chinese)

National Remote Sensing Center of China (NRSCC), Ministry of Science and Technology of the People's Republic of China, 2015. Global Ecosystems and Environment Observation: Annual Report from China (The Belt and Road Initiative Ecological and Environmental Conditions). (in Chinese)

National Development and Reform Commission (NDRC), Ministry of Foreign Affairs, Ministry of Commerce of the People's Republic of China, 2015. Vision and Actions on Jointly Building Silk Road Economic Belt and 21 st-Century Maritime Silk Road. Finance \& Accounting for Communications, (4): 82-87. (in Chinese)

Perkins-Kirkpatrick S E, Gibson P B, 2017. Changes in regional heatwave characteristics as a function of increasing global temperature. Scientific Reports, 7(1): 12256.

Wu G H, 2008. Physical Geography. Beijing: Higher Education Press. (in Chinese)

Wu S, Dai E, Huang M et al., 2007. Ecosystem vulnerability of China under B2 climate scenario in the 21st century. Chinese Science Bulletin, 52(10): 1379-1386.

Wu S H, Pan T, Liu Y H et al., 2017. Comprehensive climate change risk regionalization of China. Acta Geographica Sinica, 72(1): 3-17. (in Chinese)

$\mathrm{Xu}$ H, Qimanguli Y, Yao R et al., 2016. Environmental risk analysis and responding strategy for the Belt and Road Initiative. Chinese Journal of Environmental Management, 8(2): 36-41. (in Chinese)

Yao T D, Guo H D, 2017. Extensive third pole environment and the Belt and Road synergistic development. Bulletin of Chinese Academy of Sciences, Z2: 23-25. (in Chinese)

Xi J P, 2017. Work Together to Build the Silk Road Economic Belt and The 21st Century Maritime Silk Road: Speech at the Opening Ceremony of The Belt and Road Forum for International Cooperation (14 May 2017 , Beijing). China Economic Weekly, 20: 54-57. (in Chinese)

Zhang Q, Han L, Jia J et al., 2016. Management of drought risk under global warming. Theoretical and Applied Climatology, 125(1/2): 187-196.

Zheng D, 2008. Study on the Eco-geographical Region System of China. Beijing: The Commercial Press. (in Chinese)

Zhu J, 2017. Climate change research and observation project. Bulletin of Chinese Academy of Sciences, Z2: 29-31. (in Chinese)

Zou J L, Liu C L, Yin G Q et al., 2015. Spatial patterns and economic effects of China's trade with countries along the Belt and Road. Progress in Geography, 34(5): 598-605. (in Chinese) 